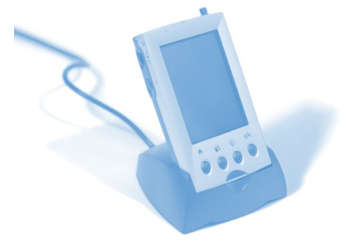

T G Harrison*, A J Shaw, K L Shallcross, S J Williams and D E Shallcross

Bristol ChemLabS

School of Chemistry

Cantock's Close

University of Bristol

Bristol

BS8 1TS

*t.g.harrison@bristol.ac.uk

\section{School-university partnerships: Lessons learned from 10 years of spectroscopy for teachers and post 16 students}

\begin{abstract}
Spectroscopy covers a wide range of analytical techniques, a small sub-set of which UK pre-university chemistry students are required to study. The expense of such equipment means that it is not available to the vast majority of schools whilst it is commonplace in university chemistry departments. This article discusses the evolution of the Bristol ChemLabS spectroscopy outreach activities. The advantages and disadvantages of this method of engagement for both the participants and the providers are discussed from 10 years of activity.
\end{abstract}

\section{Why engage schools in spectroscopy?}

For several successive changes in pre-university courses UK school students have needed to study various spectroscopic techniques. Spectroscopy is a broad term but for pre-university it can be described as a range of analytical tools and techniques used to study the way matter is assembled. For pre-university courses, these include infrared spectroscopy (IR), nuclear magnetic resonance spectroscopy (NMR), mass spectrometry (MS) and, depending on examination board for the courses undertaken, ultraviolet-visible spectroscopy (UV-Vis). Such instrumentation is out of the range of schools and it is against this background that some university chemistry departments provide opportunities that support secondary school teachers by allowing post 16 students access to this instrumentation. The students' courses do not require them to use the instrumentation. The students do need to know 'the way in which spectroscopic techniques are used to determine the molecular formulae and structures of organic compounds'. The emphasis is on problem solving rather than on spectroscopic theory ${ }^{1}$.

\section{Spectroscopy Visits to Bristol ChemLabS}

For over ten years the School of Chemistry at the University of Bristol has run spectroscopy tours and workshops for post 16 students who are studying either Advanced (A) level, the International Baccalaureate (IB) Chemistry or whose vocational course have elements of spectroscopy embedded.

The Outreach programme at the School of Chemistry began with spectroscopy tours about ten years ago. These gradually built from a few days in September, where schools would visit for a morning or afternoon session, to a whole week of morning and afternoon sessions for up to 15 schools. The format also changed in this time: as funding became available to support some local administration and as feedback was obtained, so the individual sessions were gradually modified. In the last four years the scale of this outreach activity has increased through the Bristol ChemLabS initiative ${ }^{2}$. A major difference is the role played by the school teacher fellow (STF) ${ }^{3,4}$. During the last four years an average of 400-600 students per year have visited the School of Chemistry on spectroscopy tours, a doubling of numbers from the previous five years. Many thousands more have experienced hands-on infra red or ultraviolet-visible spectroscopy through workshops and summer schools in this period and by loaning equipment to schools.

The spectroscopy tours ${ }^{5}$ are designed to promote chemistry generally and support secondary school teachers in their teaching. The spectroscopy tours take place in the autumn term with the majority in September and the remainder usually in December. The eighteen half-day experiences accommodate up to 50 students at a time.

Each half day experience comprises a two and a half hour session. The morning or afternoon visits start with a welcome and introduction to the department and a brief, general talk about spectroscopy (this was introduced in the last four years). This takes place in a lecture theatre to give the students probably their first opportunity to be in such a standard university environment. The cohort are then split into smaller, more 
manageable group sizes with an average of 10 students each, and are escorted by postgraduate chemists to the individual talks. All tours involve twenty minute sessions on mass spectrometry, infra red spectroscopy and nuclear magnetic resonance. Depending on the availability of the equipment additional talks on scanning electron microscopy and X-ray crystallography are given. Ultra violet-visible spectroscopy is used to substitute techniques that are not available for a particular session. The talks are given in the rooms where the instrumentation resides so the group size is limited to one that is both comfortable and safe. The infra red and UV-Vis spectrometers are hosted in the undergraduate teaching laboratories. As each student hears five talks this means that some demonstrators can give the same talk up to ten times per day, sometimes for several days in a row. A major modification since 2004 has been that the STF, a highly experienced former secondary school teacher, has worked with all groups to hone the twenty minute sessions and to update supporting literature given to teachers and students. (This could be achieved in collaboration with any A level chemistry teacher). Such an intervention has had a significant impact on both the deliverer and learner. Appropriate language is, of course, very important and the use of examples that are used in schools takes the learner from familiar territory onwards ${ }^{6}$. The theme of how individual techniques can provide different information on the same molecule is also a simple, yet effective innovation. Feedback is excellent for all aspects of the tour.

The postgraduate chemists involved in these spectroscopy tours, either deliver sessions or accompany students, and have all been through a Science and Engineering Ambassador Scheme (SEAS) training programme ${ }^{7}$. This national scheme, together with some informal in-house training, equips the postgraduates, many of whom are overseas students, with knowledge of the UK education system, the rights and responsibilities in working with school students and the importance of the appropriate level of communication. The postgraduate guides are encouraged to talk with the students, point out places of interest and to answer questions on all aspects of being a student as they move them around the department. Those chemists using PowerPoint slides or handouts in their talks have, of course, discussed the content with the School Teacher Fellow. The two and a half hour sessions are punctuated by a refreshments break. It has been noticeable that feedback has commented on the improved congruence of the content with that presented in school. During this period, the biggest single school group was 45 students with an entire session to themselves, and the smallest school group was just 2 . The greatest number of schools in one session was 6 .

\section{Advantages of this outreach activity}

For the students the visits to a university science department and contact with (postgraduate) students gives them insight into what it would be like for them to be an undergraduate in a practical science subject. It is common for this to be the first opportunity that the students have had to look around a university department. It is for this reason alone that the introduction to the visit takes place in a lecture theatre so that the visit is as complete an undergraduate experience as possible. Usual comments on entry to the lecture theatre include 'It's just like on TV or just like in films'! On open days students often visit with their parents. On these visits they are with their peers and there is a different dynamic. Students often ask questions about university in general and feedback suggests that this is an important opportunity to experience university that is different from open days.

For the teachers the visits serve several purposes. First, the experiences encountered by their students support their previous or future lessons. For some less experienced chemistry teachers the information given out supports their own understanding of the techniques. The brief informal discussions with those delivering the talks or with the postgraduates accompanying the groups also adds to their subject knowledge, and armoury of 'stories' and examples used by good teachers, to further enliven their lessons. Many of the teachers have no experience of the state-of-the-art instrumentation apart from pictures in the more modern text books (which are likely to be considerably out of date). Comments such as 'it's all changed beyond recognition from my day' are common.

For non-subject specialist teachers the visits give an opportunity to see a different type of university department and, for biologist and physicists, to see a different slant on their own specialisms, since all the techniques are essentially applications of physics. Some of the analyses, in a modern chemistry department, may be of biologically active specimens or of biological interest such as enzymes.

For accompanying technicians they can take the opportunity to talk with the department's technicians. Several examples of exchange of information on storage, availability of resources, safety, techniques and maintenance have been noted.

For the postgraduates, post doctoral research assistants and university technicians the events provide an opportunity to practice their science communication skills and their teaching skills. Several postgraduates report that such activities forced them to understand the technique far better than they did previously and that the activity as a whole was as much an education for them as the visiting students.

Table 1: Numbers of school students attending each session from 2005-2008.

\begin{tabular}{|c|c|c|c|c|c|c|c|}
\hline \multirow[b]{2}{*}{ Year } & \multicolumn{2}{|c|}{ September } & \multicolumn{2}{|c|}{ December } & \multirow{2}{*}{$\begin{array}{l}\text { Total Number } \\
\text { of Students } \\
\text { Attending }\end{array}$} & \multirow{2}{*}{$\begin{array}{l}\text { Total Number of } \\
\text { Schools } \\
\text { Participating }\end{array}$} & \multirow{2}{*}{$\begin{array}{l}\text { Total Number } \\
\text { of Sessions }\end{array}$} \\
\hline & $\begin{array}{l}\text { No. of } \\
\text { students }\end{array}$ & $\begin{array}{l}\text { No. of } \\
\text { sessions }\end{array}$ & $\begin{array}{l}\text { No. of } \\
\text { students }\end{array}$ & $\begin{array}{l}\text { No. of } \\
\text { sessions }\end{array}$ & & & \\
\hline 2005 & 411 & 12 & 88 & 2 & 499 & 30 & 14 \\
\hline 2006 & $\sim 500$ & 11 & 150 & 4 & 650 & 29 & 15 \\
\hline 2007 & 402 & 12 & (Nov) 90 & 2 & 492 & 24 & 18 \\
\hline 2008 & 428 & 10 & 94 & 2 & 522 & 24 & 18 \\
\hline
\end{tabular}


For the university there is an element of promotion with the schools engaged. Frequently photographs taken during the visits end up in school websites, posters in the science departments or school newsletters. More importantly it provides an informal opportunity for members of the academic staff to talk with teachers to find out what is currently going on in schools. The heavy involvement in outreach activity featured prominently in a recent very large, successful grant application to replace NMR instruments and increase their number.

\section{Disadvantages}

Whilst a few visiting students can experience hands-on spectroscopy with IR and UV-Vis not all can. Even undergraduates do not typically handle some modern instrumentation, such as NMR and mass spectrometers, as the instruments have dedicated technical staff to run samples submitted to them.

For the teachers the timing of the tours within the year does not always coincide with convenient times either because of local rules such as 'no school trips in the first month (September) of the school year' or the 'rarely cover' policy or because some for the spectroscopic techniques are yet to be covered in lessons. The 'rarely cover' policy was put in place in 2009 to ensure that teachers 'rarely cover' the classes of colleagues who are absent. However, if the activity has been booked in advance, as suggested, this should include provision for teacher cover and will not be affected by this new policy. It should be noted that this policy was not designed to prevent outside activities but to ensure that teachers are not overloaded with additional teaching; therefore the need for good planning and preparation is essential. Due to the need for the valuable instrumentation to be available for their prime use in teaching undergraduates and research we can normally only provide these tours in September and December each year. Other outreach activities at different times of the year make demands on resources.

For the School of Chemistry there are nine days per year when the various facilities are not working to their normal capacity for their prime function. However, the timing within the year is such that there is no workload being generated by the undergraduates as the spectroscopy visits are normally out of undergraduate term time. There is also a considerable secretarial input into the communication and management of both large numbers of schools and staff involved. As this is now a well established annual series of events the School of Chemistry considers that the advantages outweigh the disadvantages!

\section{Financial support}

There are of course costs associated with activity at this level. Funding in recent years has come from three sources. Bristol's School of Chemistry pays the salaries and running costs of the academic staff, secretarial support and post doctoral chemists. The local section of the Royal Society of Chemistry contributes financially to the costs of the consumables and, as of 2008; the schools themselves are making a nominal payment per student for the experience.

\section{The Value of the Visits to us}

It should be noted that these visits are not just of benefit to the students and their teachers. As we have noted in previous publications $s^{3,4}$, there are many benefits to the department. First, having run this activity for such a long time we have been able to work with teachers to shape and modify the activity and this dialogue has naturally moved beyond just the spectroscopy tours. Therefore, a major benefit is that it has opened up meaningful and useful dialogue with teachers that have informed us about new aspects of curricula and new teaching methods. Second, the handouts we have produced have gone through numerous teachers and students who have provided clear and expert feedback. Such feedback has not only improved these handouts but has also influenced first year material and in particular induction week. Third, over the course of this project, postgraduate students have done more of the demonstrating, e.g. infra red and ultra violet spectroscopy. All students have reported that this has been extremely beneficial to them, because they have been able to hone their communication skills and because it has forced them to really understand the technique they are demonstrating. The many questions they have been asked by teachers and students have improved their knowledge of the various spectroscopic techniques as they have then had to ask a senior colleague when they didn't know the answer. In two cases we know about, these interactions have had a direct positive impact on their $\mathrm{PhD}$ studies as they have found out about an analysis that they could do which has propelled their research forward. There is little doubt that there are many more of these cases that are not captured by us in our debriefing sessions with postgraduates and staff. Fourth, in interviews, postgraduate students have used these sessions to talk about times when they have solved problems or shown initiatives and several report that interviewers have been impressed with their responses. Fifth, over the years about one third of the academic staff have taken part in various aspects of the spectroscopy tours and this has been beneficial to them in two ways; they have interacted with students and teachers first hand and enjoyed several useful discussions, second, they have been able to build up a portfolio of interactions that they can put on grant applications illustrating a different type of impact. In one direct example, sponsorship from an instrument manufacturer, that lent weight to an ultimately successful grant application for new NMR machines, was directly related to the success of the tours. Sixth, this activity brings together people in the department who would not normally interact in the general running and operation; that in itself is a good thing. However, there are examples over the course of this long-term project where this has benefitted the running of the department (e.g. input into first and second year teaching modules) and has brought PhD students into contact with new academics, with several discussions leading to interesting and fruitful collaborations. Finally, the diversity of schools visiting the department has increased and new schools are added each year. This activity was never designed to increase recruitment but it is no coincidence that students from schools who come to these events apply to Bristol. 


\section{Monitoring}

The common question asked by many funders of outreach activity is 'How do you know what you are providing is of any value or doing any good?' Most evidence is qualitative through discussions with teachers and students. In an attempt to quantify the value of each talk, questionnaires are given to accompanying teachers. Teachers handle these in one of two ways: either they give a teacher's impression or they seek feedback from their students collectively. Such feedback has informed the level of language and examples used in presentations and any literature given, the role of the accompanying postgraduates, the inclusion of ultravioletvisible spectroscopy and, for next year, time-of-flight (TOF) mass spectrometry. Some suggestions cannot be addressed for various reasons, such as the scheduling of tours at other times of the school year. Participating staff and postgraduates also give informal feedback.

'........ They [the students] were wowed by the machinery and what it could do. All that theoretical A-Level stuff seems so much more real now. I have to say that Sue and I were also pretty gob-smacked by some of the up-todate versions of what we used when we were undergrads!'

This, from a recent teacher via unsolicited email is typical of the replies.

Additional quantitative feedback can be gained by noting the number of students and schools on waiting lists because the sessions are full, looking at the distance travelled by visiting schools as a possible function of the value of experience and the number of schools making or wishing to make repeat visits. We also carried out some data analysis to see whether there was any significant correlation with examination results. Surprisingly, there does appear to be some correlation, although we are extremely hesitant to read anything into these data.

\section{Correlation with Exam Results of Schools in CHeMneT}

As part of the research on schools in our network, called $\mathrm{CHeMneT}$, data were collected on A-level performance, focusing on two measures:

- $\%$ of high performing students achieving A or B in A-level Chemistry, and

- $\%$ of students achieving A - E in A-level Chemistry.

These data were collected from science teachers, schools' examinations officers or school websites (Table 2).

Independent-samples t-tests were run using the Statistical Package for the Social Sciences (SPSS) to establish whether there were any statistically significant differences between the average results of engaged and non-engaged schools. The $\mathrm{p}$-values indicate whether the difference in average percentages was significant at the $95 \%$ confidence level. It is of course very important to note that several caveats must be taken into consideration when looking at these data and these will be discussed later.
Inspection of students achieving grades A-E in chemistry suggests that the schools that have engaged with Bristol ChemLabS have on average a significantly higher percentage of students obtaining those grades, in 07/08 and 05/06 than those that do not. The significant differences (for $A-E$ grades rather than $A / B$ grades) suggest that any effect is impacting most on students at the lower end of the spectrum, rather than the top performing students. It may be that the spectroscopy tours themselves are having an impact but equally likely is the fact that the visit selects out those students who want to do well at $A$ level in Chemistry. There are several confounding factors that could lead to any elevation in results. For example, by the very fact that the school/class have attended, this may indicate a more engaged and enthusiastic teacher and this may influence results. However, there are a few possible reasons for an enhancement based on the visits. First, the visit may inspire the students to come to University and especially those at the lower end. Second, seeing the equipment and talking with postgraduates, academics and technicians may help the students to understand topics in this area that they didn't understand. What is clear is that far more data are required to ascertain whether there is an impact on results and such analysis is on-going.

\section{Bristol ChemLabS' top tips for running similar activities}

- Use well trained postgraduates as guides and technical helpers who are used to working with school students.

- Give schools plenty of notice so they can act on the offer of this type of outreach.

- Make the activity available at the same time each year so that teachers can build it into their schemes of work from one year to the next.

- Once established do not be afraid to ask for a token charge for the activity. This not only helps recover costs and makes such a programme sustainable but severely reduces the 'no shows'.

- If in doubt about the suitability of content enlist the help, in advance, of two or three local teachers and get them to feedback on their own examination course requirements. Whilst this can be obtained from the relevant examination specifications the teachers will understand the interpretation.

- Provide a refreshment break with biscuits and a variety of drinks. The school students like being made welcome and those participating in the delivery will need a break too. The interval also allows the accompanying teachers to talk with their students about what they have seen and to answer questions. It also allows teachers to informally ask questions of university staff and postgraduates present. 


\section{Conclusion}

The spectroscopy outreach programmes offered by universities such as Bristol are very popular, providing not only an opportunity to see equipment that students would not have access to, but at the same time allowing students to have a brief experience of University. Provided that the level of the communication is appropriate and the content supports the examination requirements the availability of a regular programme can be an important engagement activity for a chemistry department with all the benefits that this entails. The inclusion of teachers in the programme preparation from the content through to the training of the postgraduates is important. Whichever format of visit is offered, this is valuable to all parties. We have seen that regular revision and regular but modest modifications of the programme have gradually made the activity very useful for both the provider and the recipient.

\section{Acknowledgments}

We thank Bristol ChemLabS, the Bristol Local section of the RSC and DES thanks the Higher Education Academy (HEA) for a National Teaching Fellowship.

\section{References}

1. GCE Chemistry Specification for AS exams 2009 onwards and A2 exams 2010 onwards (version 1.0), The Assessment and Qualifications Alliance, p 17. Also available via

<www.aqa.org.uk/qual/gce/pdf/AQA-2420-W-SP-10.PDF> (last accessed $16^{\text {th }}$ May 2010).

2. <www.chemlabs.bris.ac.uk/overview.htm> (last accessed $24^{\text {th }}$ May 2010).

3. Shallcross D. E., and Harrison T.G. (2007), A secondary School Teacher Fellow within a university chemistry department: the answer to problems of recruitment and transition from secondary school to University and subsequent retention? Chemistry Education Research and Practice, 8 (1), 101-104.

4. Shallcross, D.E. and Harrison, T.G. (2007) The impact of School Teacher Fellows on teaching and assessment at tertiary level, New Directions, 3, 77-78.

5. Harrison T.G., and Shallcross D.E. (2006), Perfume chemistry, sexual attraction and exploding balloons: university activities for school, Science in School, 3, 48-51.

6. Ausubel, D.P., Stager, M. and Gaite, A.J.H. (1968), Retroactive facilitation in meaningful verbal learning, J. Ed. Psychology, 59, 250.

7. <www.stemnet.org.uk/ambassadors_seas.cfm> (last accessed 30th March 2010). 